\title{
Influência de diferentes metodologias de esterilização sobre a atividade antifúngica de extratos aquosos de plantas medicinais
}

\author{
VENTUROSO, L.R.*; BACCHI, L.M.A.; GAVASSONI, W.L.; PONTIM, B.C.A.; CONUS, L.A. \\ Universidade Federal da Grande Dourados, Faculdade de Ciências Agrárias, Rodovia Dourados-Itahum km 12, \\ Caixa Postal 533. CEP: 79804-970, Dourados-Brasil *luck_rv@hotmail.com
}

\begin{abstract}
RESUMO: Foram conduzidos no Laboratório de Fitopatologia da Universidade Federal da Grande Dourados três experimentos com o objetivo de avaliar in vitro a atividade antifúngica dos extratos aquosos de alho, canela e cravo-da-índia, submetidos a diferentes processos de desinfestação e/ou esterilização sobre o desenvolvimento de Fusarium solani. O delineamento experimental utilizado para cada ensaio foi inteiramente casualizado, com 5 tratamentos e 8 repetições. Utilizaram-se os extratos aquosos na concentração de $20 \%$, submetidos às metodologias de filtragem (FI), banho maria a $65^{\circ} \mathrm{C}(\mathrm{BM})$, autoclavagem a $100^{\circ} \mathrm{C}(\mathrm{AT} 1)$, autoclavagem a $120^{\circ} \mathrm{C}$ (AT2) e a testemunha (somente BDA). Posteriormente os extratos foram incorporados em meio $\mathrm{BDA}$, acondicionados em placas de Petri, onde foram transferidos discos de micélio de $F$. solani medindo $0,3 \mathrm{~cm}$ de diâmetro. Após, as placas foram incubadas a $25^{\circ} \mathrm{C}$, com fotoperíodo de 12 horas. Os tratamentos foram analisados em relação ao crescimento micelial da colônia, a porcentagem de inibição e a taxa de crescimento de $F$. solani. Foi observado em todos os ensaios maior crescimento do fungo na testemunha, evidenciando o potencial antifúngico dos extratos. Foi observada influência da metodologia de esterilização sobre a eficiência dos extratos de alho e canela. Para o alho a FI proporcionou os melhores resultados, enquanto que para o extrato de canela não houve diferenças entre as metodologias FI, BM e AT1. As diferentes metodologias utilizadas não interferiram na eficiência do extrato aquoso de cravo-da-índia.
\end{abstract}

Palavras-chave: Allium sativum, Cinnamomum zeylanicum, Syzygium aromaticum

\begin{abstract}
Influence of different sterilization methods on the antifungal activity of aqueous extracts of medicinal plants. Three experiments were conducted in the Laboratory of Phytopathology of Federal University of Grande Dourados, Mato Grosso do Sul State, Brazil, to evaluate in vitro the antifungal activity of aqueous extracts of garlic, cinnamon and clove subjected to different processes of disinfection and/or sterilization against the development of Fusarium solani. The experimental design for each trial was completely randomized, with 5 treatments and 8 replicates. Aqueous extracts at a concentration of $20 \%$ were subjected to the methods of filtering (FI), water bath at $65^{\circ} \mathrm{C}(\mathrm{WB})$, autoclaving at $100^{\circ} \mathrm{C}(\mathrm{AT} 1)$, autoclaving at $120^{\circ} \mathrm{C}$ (AT2) and control treatment (PDA alone). Subsequently, the extracts were incorporated into PDA medium, added to Petri dishes, to where $F$. solani mycelium discs of $0.3 \mathrm{~cm}$ diameter were transferred. Then, the plates were incubated at $25^{\circ} \mathrm{C}$ with 12 -h photoperiod. The treatments were analyzed as to mycelial growth of the colony, percentage of inhibition and growth rate of $F$. solani. Increased fungal growth was observed for the control treatment, demonstrating the antifungal potential of the extracts. The sterilization method influenced the efficiency of garlic and cinnamon extracts. For garlic, Fl led to the best results, whereas for cinnamon extract there were no differences among the methodologies FI, WB and AT1. The different methods used did not interfere with the efficiency of the aqueous extract of clove.
\end{abstract}

Key words: Allium sativum, Cinnamomum zeylanicum, Syzygium aromaticum

Recebido para publicação em 29/04/2009

Aceito para publicação em 02/05/2010

Rev. Bras. PI. Med., Botucatu, v.12, n.4, p.499-505, 2010. 


\section{INTRODUÇÃO}

O controle das doenças na agricultura tem se intensificado, sendo realizado basicamente através do emprego de produtos sintéticos. Quando estes produtos são utilizados de maneira racional, podemse obter resultados satisfatórios. Entretanto, a adoção indiscriminada tem ocasionado problemas de contaminação humana e ambiental, e tem provocado a seleção de patógenos resistentes a esses produtos químicos (Ghini \& Kimati, 2000). A busca de substitutos para estes produtos encontra nas plantas uma alternativa de interesse econômico e ecológico bastante promissor (Souza et al., 2007).

Na natureza, há grande quantidade de plantas que se apresentam resistentes a diferentes patógenos, e essa resistência pode estar relacionada à existência de substâncias com propriedades fungicidas naturalmente produzidas por elas (Lemos et al., 1990). Existe grande quantidade de metabólitos secundários das plantas medicinais que foram isolados e identificados em relação à estrutura química, porém, ainda não foram estudados quanto às atividades biológicas. A obtenção dos metabólitos secundários dessas plantas, bem como, a determinação da atividade biológica dessas moléculas, com respeito à atividade elicitora e/ou antimicrobiana poderá contribuir para a aquisição de maiores conhecimentos que reforçam a possível utilização como um método alternativo de controle de doenças de plantas (SchwanEstrada et al., 2000).

Estudos têm demonstrado que óleos essenciais e extratos aquosos obtidos de algumas espécies vegetais têm se mostrado eficientes no controle de doenças de plantas, tanto pela ação fungitóxica direta, como indiretamente, por meio da indução de resistência às culturas tratadas (Stangarlin et al., 1999). Como exemplos, têm-se o controle da mancha marrom (Bipolaris sorokiniana) em trigo usando extrato aquoso de cânfora (Artemisia camphorata Vill.) (Franzener et al., 2003), do oídio (Oidium lycopersici) do tomateiro pelo óleo emulsionável de nim (Azadirachta indica A. Juss.) (Carneiro, 2003), da requeima (Phytophthora infestans) da batata pelo extrato de cavalinha (Equisetum sp.) (Ke-Qiang \& Bruggen, 2001), da antracnose (Colletotrichum lagenarium) em pepino pelo extrato de eucalipto (Eucalyptus citriodora Hooker M.) (Bonaldo et al., 2004), da mancha angular (Phaeoisariopsis griseola) do feijoeiro pelo extrato de sementes de nim (Azadirachta indica A. Juss.) (Carneiro et al., 2008).

A importância do fungo Fusarium solani (Mart.) Hans tem sido relacionada aos elevados danos econômicos causados no setor agrícola e também, pela distribuição cosmopolita (Ghini \& Nakamura, 2001). Em função da capacidade de sobrevivência no solo e em restos culturais, podem causar tombamento de pré e pós-emergência, bem como, podridões radiculares em diversas culturas (Bianchini et al., 2005). O patógeno pode ainda ser transmitido, para novas regiões produtoras, por meio de sementes contaminadas (Balardin et al., 2005), requerendo a adoção de medidas de controle.

Os eficientes resultados constatados com a utilização de extratos vegetais no controle de fungos fitopatogênicos têm enquadrado esta prática como promissora dentre os controles alternativos utilizados. Porém, para que os extratos vegetais possam agir de forma mais eficiente é necessário conhecer o modo de ação dos princípios ativos. Rodrigues et al. (2006), trabalhando com a planta alfavaca-cravo (Ocimum gratissimum $L$.), verificaram que o extrato bruto aquoso quando autoclavado induziu maior inibição do crescimento micelial em todas as concentrações utilizadas comparado ao extrato bruto esterilizado por filtração, e afirmaram que o princípio ativo da planta não seria termosensível. Os autores destacam ainda que na concentração de $50 \%$, o extrato bruto autoclavado proporcionou inibição de $100 \%$ do crescimento micelial de Bipolaris sorokiniana. Já Ribeiro \& Bedendo (1999) verificaram que o extrato de alho (Allium sativum L.) esterilizado através de filtragem em filtro bacteriológico apresentou atividade antifúngica, contrariamente ao extrato autoclavado que perdeu esta característica durante a esterilização, evidenciando que o princípio ativo envolvido seria termosensível.

A exposição de extratos vegetais a altas temperaturas tem indicado que a esterilização por meio de autoclavagem a $120^{\circ} \mathrm{C}$ seria a metodologia que tem proporcionado maiores alterações nos compostos secundários das plantas. Franzener et al. (2003) verificaram que o efeito antifúngico direto do extrato aquoso de cânfora (Artemisia camphorata Vill.) sobre a germinação de esporos foi grandemente afetado quando o extrato foi autoclavado, pois o mesmo não inibiu a germinação de esporos de Bipolaris sorokiniana, indicando, possivelmente, a presença de um composto fungitóxico termolábil. Celoto et al. (2008) observaram que os extratos submetidos à autoclavagem, independentemente de serem aquosos ou hidroetanólicos, apresentaram menor atividade antifúngica, indicando que as condições de autoclavagem alteram a substância antifúngica dos mesmos.

A diversidade de substâncias ativas em plantas medicinais tem motivado o desenvolvimento de pesquisas envolvendo extratos vegetais, tendo em vista o controle in vitro de fitopatógenos. Entretanto, existe a necessidade da pesquisa detectar essas substâncias e também a melhor metodologia na obtenção dos extratos, de modo a otimizar o efeito dessas propriedades.

No intuito de evitar contaminações com microrganismos, que interferem nos resultados das pesquisas envolvendo o uso de extratos vegetais, tem-

Rev. Bras. PI. Med., Botucatu, v.12, n.4, p.499-505, 2010. 
se utilizado distintas metodologias visando promover a desinfestação ou mesmo a esterilização destes extratos. Na literatura existem muitos trabalhos que avaliam o uso de extratos vegetais obtidos por meio de filtragem e autoclavagem a $120^{\circ} \mathrm{C}$, no entanto, quando se considera os aspectos térmicos há grande amplitude nessas metodologias, tornando-se de suma importância analisar com mais detalhes o efeito destas metodologias sobre a atividade antifúngica dos extratos vegetais. Diante do exposto, o trabalho teve por objetivo avaliar in vitro a eficiência dos extratos aquosos de alho (Allium sativum L.), canela (Cinnamomum zeylanicum Breym) e cravo-da-índia (Syzygium aromaticum (L.) Merr. \& Perry), submetidos a diferentes processos de desinfestação e/ou esterilização sobre o desenvolvimento de Fusarium solani.

\section{MATERIAL E MÉTODO}

Os experimentos foram realizados no Laboratório de Fitopatologia da Universidade Federal da Grande Dourados (UFGD) no período de março a junho de 2008. Foi conduzido um ensaio experimental para cada planta medicinal utilizada, sendo estas, alho (Allium sativum L., Liliaceae), canela (Cinnamomum zeylanicum Breym, Lauraceae) e cravo-da-índia (Syzygium aromaticum (L.) Merr. \& Perry, Myrtaceae).

O delineamento experimental utilizado foi inteiramente casualizado, com 5 tratamentos e 8 repetições, para cada ensaio. Os tratamentos constaram das metodologias de desinfestação e/ou esterilização de filtragem (FI) em papel wathman no 1; banho maria a $65^{\circ} \mathrm{C}$, por um período de 1 hora (BM); autoclavagem a $100^{\circ} \mathrm{C}$ (AT1) e autoclavagem a $120^{\circ} \mathrm{C}$ (AT2), ambos durante 20 minutos, e a testemunha, onde utilizou-se somente o meio de cultura Batata-Dextrose-Agar (BDA).

As plantas medicinais foram coletadas no Horto de Plantas Medicinais da UFGD e em produtores locais, no mês de março. Para obtenção dos extratos aquosos, foram coletados $20 \mathrm{~g}$ do material vegetal, bulbos de alho, casca de canela e botão floral de cravo-da-índia e triturados em liquidificador, com $100 \mathrm{~mL}$ de água destilada.

Posteriormente à obtenção, os extratos aquosos foram submetidos às metodologias de esterilização. Em seguida foram incorporados em meio BDA fundente, de modo a obter concentração de 20\% (concentração adotada, pelo Laboratório de Fitopatologia da UFGD, em estudos com extratos vegetais), e acondicionados em placas de Petri. No tratamento testemunha havia apenas o meio BDA. Uma hora após verter-se o meio BDA, transferiu-se no centro das placas, discos de micélio de Fusarium solani medindo $0,3 \mathrm{~cm}$ de diâmetro, retirados de colônias puras com 7 dias de crescimento. $O$ isolado fúngico foi obtido junto à Embrapa Soja.
As placas de Petri foram vedadas com filme plástico e incubadas em câmara BOD a uma temperatura de $25^{\circ} \mathrm{C}$, com fotoperíodo de 12 horas, regime de luz mais próximo as condições naturais, segundo Teixeira et al. (2001).

Analisaram-se as variáveis, crescimento micelial, porcentagem de inibição do crescimento e taxa de crescimento micelial. Para avaliação do crescimento micelial das colônias fúngicas foram realizadas medições do crescimento radial da colônia em dois eixos ortogonais, sendo posteriormente calculada a média. As leituras foram realizadas a cada quatro dias, perdurando até o momento em que as colônias atingiram $3 / 4$ da superfície do meio de cultura (Stangarlin et al., 1999). A porcentagem de inibição do crescimento (PIC) dos fitopatógenos foi obtida por meio da fórmula: $P I C=[($ diâmetro da testemunha - diâmetro do tratamento)/diâmetro da testemunha] x 100, para cada extrato em relação a testemunha. A taxa de crescimento dos fitopatógenos foi mensurada conforme Benício et al. (2003), onde os dados foram plotados para obtenção de equação de regressão linear simples $(y=a+b x)$, sendo $(x)$ o dia final da incubação, (y) o diâmetro final da colônia, (a) o diâmetro inicial da colônia e (b) a taxa de crescimento micelial, determinada pelo coeficiente de regressão.

Os dados foram transformados em $\sqrt{ } x+1$, submetidos à análise de variância com auxílio do programa SISVAR, e as médias comparadas pelo teste de Tukey a $5 \%$ de probabilidade.

\section{RESULTADO E DISCUSSÃO}

No ensaio experimental com extrato de alho, foi observado em todos os dias de incubação maior crescimento de Fusarium solani no tratamento controle, evidenciando o potencial antifúngico do extrato. O crescimento micelial do patógeno foi influenciado pela metodologia de esterilização a que o extrato foi submetido, logo na primeira leitura, verificando atividade antifúngica significativamente superior do extrato de alho FI e BM (Figura 1).

No decorrer do período de incubação dos tratamentos, foi constatado a partir do oitavo dia, que o extrato aquoso de alho submetido à metodologia $\mathrm{Fl}$, proporcionou o menor crescimento de $F$. solani, seguido pelos tratamentos BM, AT1 e AT2. Fato que vem a evidenciar menor influência da filtragem sobre os princípios antifúngicos do extrato. O tratamento $\mathrm{BM}$ apresentou menor crescimento comparado às metodologias AT1 e AT2, porém, quando comparado com o extrato $\mathrm{FI}$, resultou em maior crescimento do patógeno a partir da segunda leitura.

Resultados semelhantes foram relatados por Ribeiro \& Bedendo (1999), que avaliando o efeito inibitório de extratos vegetais sobre Colletotrichum gloeosporioides, observaram atividade antifúngica do

Rev. Bras. PI. Med., Botucatu, v.12, n.4, p.499-505, 2010. 
extrato de alho filtrado, sendo esta atividade perdida quando o mesmo foi submetido à esterilização por meio de autoclavagem. Concluíram os autores que 0 princípio ativo da planta seria termosensível. Os resultados obtidos por Roswalka et al. (2008), que avaliaram o efeito fungitóxico de vinte plantas, evidenciaram a existência de metabólitos biologicamente ativos nestas plantas, entretanto, foi verificado que os extratos quando submetidos à decocção proporcionaram a Glomerella cingulata maior crescimento micelial. Bonaldo et al. (2004) verificaram comportamento diferenciado em relação àqueles constatados no ensaio com extrato aquoso de alho, pois os autores observaram que o extrato de Eucalyptus citriodora quando autoclavado proporcionou maior atividade antifúngica, inibindo em $90 \%$ a germinação de esporos de Colletotrichum lagenarium, quando comparado ao extrato filtrado, no qual foi relatada máxima inibição de $75 \%$.

A possibilidade de existirem metabólitos secundários de plantas que se apresentem termosensíveis é reforçada por Franzener et al. (2003). Os autores avaliaram a atividade antifúngica do extrato de cânfora, e constataram que o extrato autoclavado não inibiu a germinação de esporos de Bipolaris sorokiniana.

No ensaio realizado com extrato aquoso de canela foi observado crescimento micelial de Fusarium solaniem todos os tratamentos estudados, porém com diferenças em relação ao diâmetro das colônias, verificado em função das metodologias de esterilização a que os extratos foram submetidos (Figura 2).

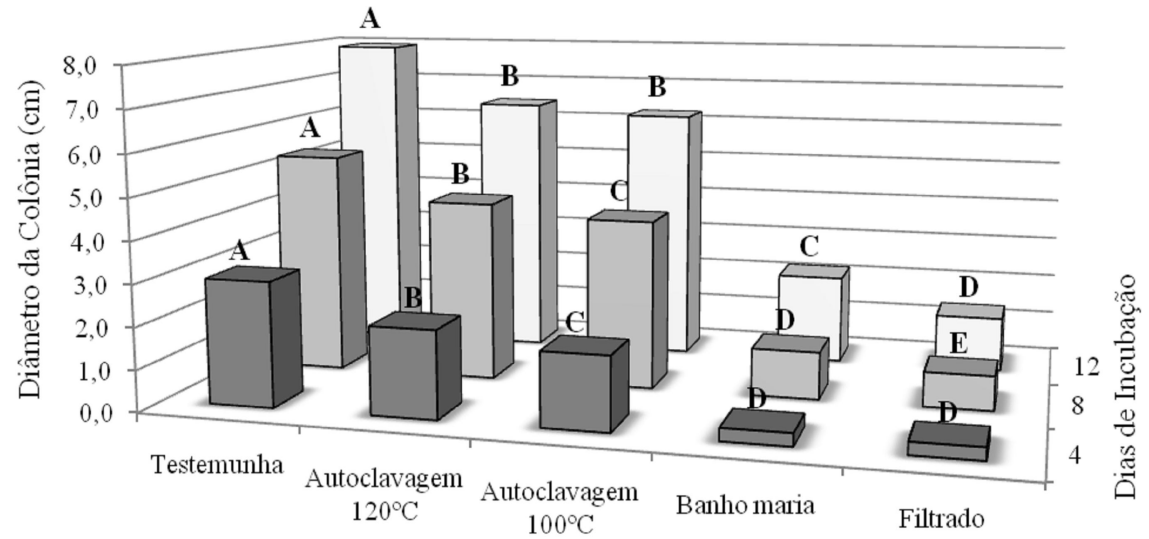

Metodologia de Esterilização

FIGURA 1. Crescimento micelial de Fusarium solani, submetido ao extrato aquoso de alho realizado a partir de diferentes metodologias de esterilização. Dourados - MS, 2008. Médias seguidas pela mesma letra nas linhas, não diferem entre si pelo teste de Tukey a $5 \%$ de probabilidade.

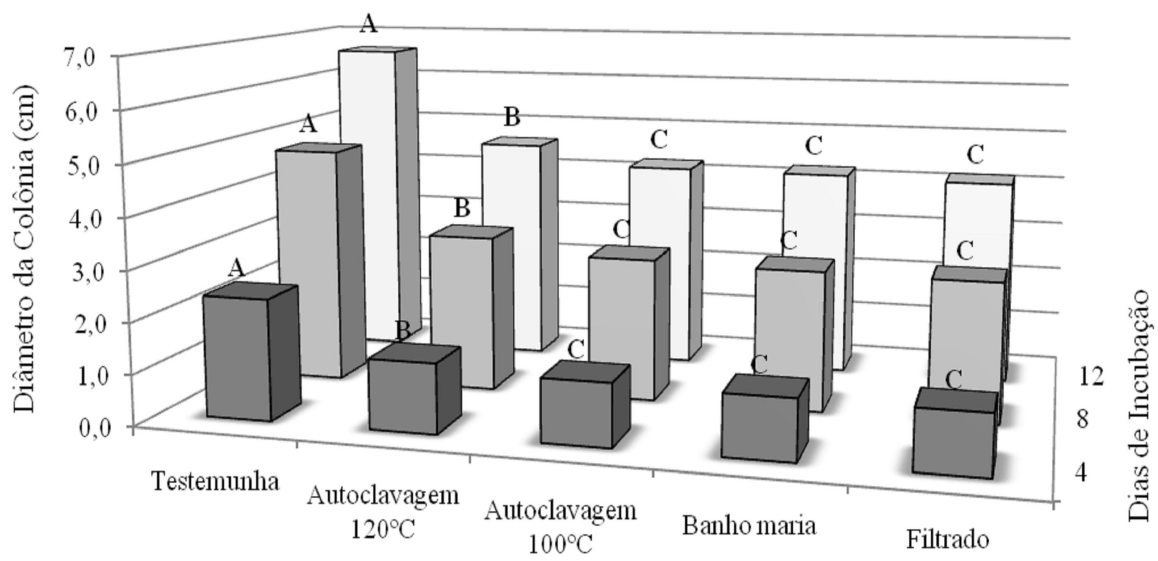

Metodologia de Esterilização

FIGURA 2. Crescimento micelial de Fusarium solani, submetido ao extrato aquoso de canela realizado a partir de diferentes metodologias de esterilização. Dourados - MS, 2008. Médias seguidas pela mesma letra nas linhas, não diferem entre si pelo teste de Tukey a $5 \%$ de probabilidade. 
Nota-se na Figura 2, em todas as leituras realizadas durante o período de incubação, o mesmo comportamento no crescimento micelial de $F$. solani frente às metodologias de esterilização a que 0 extrato de canela foi submetido. Foi observado maior crescimento micelial do fungo no tratamento controle, sendo verificado dentre as metodologias de esterilização do extrato aquoso, menor atividade antifúngica quando autoclavado a $120^{\circ} \mathrm{C}$, em relação às demais metodologias utilizadas. $\mathrm{O}$ extrato aquoso quando $\mathrm{FI}, \mathrm{BM}$ eAT1 resultaram em menor crescimento do patógeno, 4,13, 4,19 e 4,21 cm, respectivamente, apresentando valores semelhantes entre si.

As metodologias de esterilização e/ou desinfestação utilizadas no ensaio com extrato aquoso de cravo-da-índia não influenciaram a atividade antifúngica do mesmo, como foi observado nos ensaios com os extratos de alho e canela (Figura 3). Com a utilização do extrato aquoso de cravo-da-índia não foi observado crescimento micelial de $F$. solani, perante as metodologias testadas, no período de incubação estudado. Observa-se, que apenas no tratamento testemunha o fungo apresentou crescimento, evidenciando maior atividade antifúngica e maior estabilidade dos princípios ativos do cravoda-índia, em relação às demais plantas estudadas.

Rodrigues et al. (2006), em trabalho com a planta Ocimum gratissimum, além de não observarem efeitos negativos da autoclavagem, verificaram ainda, que o extrato bruto quando submetido a esta metodologia de esterilização foi mais eficiente na redução do crescimento micelial de Bipolaris sorokiniana, comparado ao extrato bruto esterilizado por meio de filtragem. Segundo os autores, o aumento nas concentrações do extrato bruto aquoso, aliado à temperatura de autoclavagem $\left(121^{\circ} \mathrm{C}\right)$, pode ter ativado ou transformado algum composto do metabolismo secundário da planta, otimizando a ação fungicida e/ou fungitóxica.

O extrato de cravo-da-índia proporcionou total inibição no crescimento de $F$. solani, em todas as metodologias a que o mesmo foi submetido (Tabela 1), evidenciando que o extrato desta planta pode ser submetido aos diferentes métodos, sem que o mesmo perca o potencial fungistático no controle in vitro do patógeno.

As menores porcentagens de inibição observadas com a utilização dos extratos aquosos de alho e canela ocorreram quando os mesmos foram

TABELA 1. Inibição do crescimento (\%) micelial de F. solani submetido a extratos vegetais realizado por diferentes metodologias de esterilização. Dourados, MS, 2008.

\begin{tabular}{cccc}
\hline & \multicolumn{3}{c}{ Extratos Vegetais } \\
\hline $\begin{array}{c}\text { Metodologias de } \\
\text { esterilização }\end{array}$ & Alho & Canela & $\begin{array}{c}\text { Cravo- } \\
\text { da-índia }\end{array}$ \\
\hline Filtragem & $86,5 \mathrm{a}$ & $37,5 \mathrm{a}$ & $100,0 \mathrm{a}$ \\
Banho maria & $75,4 \mathrm{~b}$ & $36,5 \mathrm{a}$ & $100,0 \mathrm{a}$ \\
Autoclavagem a $100^{\circ} \mathrm{C}$ & $22,1 \mathrm{c}$ & $36,3 \mathrm{a}$ & $100,0 \mathrm{a}$ \\
Autoclavagem a $120^{\circ} \mathrm{C}$ & $19,3 \mathrm{~d}$ & $30,3 \mathrm{~b}$ & $100,0 \mathrm{a}$ \\
Testemunha & $0,0 \mathrm{e}$ & $0,0 \mathrm{c}$ & $0,0 \mathrm{~b}$ \\
\hline CV (\%) & 3,66 & 3,30 & 0,00 \\
\hline
\end{tabular}

Médias seguidas pela mesma letra nas colunas, não diferem entre si pelo teste de Tukey a $5 \%$ de probabilidade.

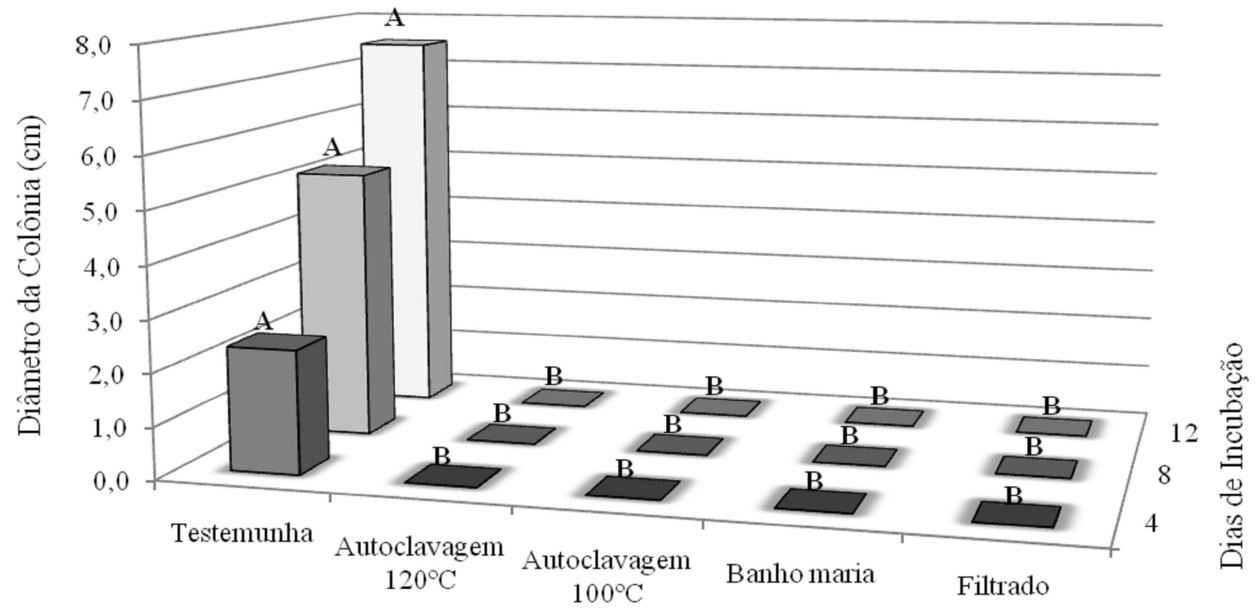

Metodologia de Esterilização

FIGURA 3. Crescimento micelial de Fusarium solani, submetido ao extrato aquoso de cravo-da-índia realizado a partir de diferentes metodologias de esterilização. Dourados - MS, 2008. Médias seguidas pela mesma letra nas linhas, não diferem entre si pelo teste de Tukey a $5 \%$ de probabilidade. 
submetidos à esterilização por meio de autoclavagem a $120^{\circ} \mathrm{C}$, verificando inibição de 19,3 e $30,3 \%$, respectivamente. Analisando as porcentagens obtidas pelos extratos aquosos quando se adotou a metodologia $\mathrm{FI}$, pode-se afirmar que os princípios ativos encontrados no alho apresentam menor estabilidade frente às variações de temperaturas, que envolvem a obtenção do extrato.

Com a utilização do extrato aquoso de alho, foi verificada relação inversamente proporcional, onde conforme se aumentava a temperatura nas metodologias de esterilização, menores porcentagens de inibição do crescimento de $F$. solanieram obtidas. Observou-se incremento na inibição do fungo de mais de $67 \%$, com a utilização do extrato Fl em comparação ao extrato AT2. Este fato pode estar associado à presença dos compostos sulfurados encontrados no alho, maiores responsáveis pela fungitoxidade, visto que os mesmos são sensíveis a ação do calor.

$O$ extrato aquoso de canela apresentou pequena variação na porcentagem de inibição de $F$. solani, não sendo constatadas diferenças significativas entre as metodologias FI, BM e AT1. Porém, quando se adotou a metodologia AT2 notouse que a atividade antifúngica do extrato passa a apresentar ligeira influência, ocasionando inibição inferior às demais metodologias.

Avaliando a atividade antifúngica de extratos vegetais no controle de Colletotrichum gloeosporioides, Celoto et al. (2008) verificaram com a utilização da metodologia de esterilização por meio de autoclavagem, que dos vinte extratos aquosos testados, apenas cinco deles, bucha (Luffa acutangula (L.) Cogn.), espirradeira (Nerium oleander L.), eucalipto (Eucalyptus citriodora Hooker M.), mentrasto (Peltodon radicans Pohl) e unha-de-vaca (Bauhinia spp.), proporcionaram inibição significativamente superior aos extratos filtrados. Estes resultados salientam a importância de se conhecer a metodologia que proporcione aos metabólitos secundários das plantas maiores fungitoxidade, contribuindo na busca por técnicas que possam ser testadas no controle de doenças in vivo.

A taxa de crescimento micelial de $F$. solani apresentou diferenças significativas, decorrentes das diferentes metodologias de esterilização e/ou desinfestação utilizadas na obtenção dos extratos aquosos de alho e canela. Não foi verificado crescimento do fungo na presença do extrato aquoso de cravo-da-índia (Tabela 2).

A variabilidade observada na taxa de crescimento de $F$. solani dentro de cada extrato aquoso utilizado, em função da metodologia de esterilização, reflete com clareza a importância da pesquisa no que se refere a encontrar alternativas práticas, que possam aumentar a eficácia dos extratos vegetais no controle de fitopatógenos.
TABELA 2. Taxa de crescimento micelial ( $\left.\mathrm{cm} \mathrm{dia}^{-1}\right)$ de Fusarium solani submetido ao tratamento com extratos vegetais realizado por diferentes metodologias de esterilização. Dourados, MS, 2008.

\begin{tabular}{cccc}
\hline & \multicolumn{3}{c}{ Extratos Aquosos } \\
\cline { 2 - 4 } $\begin{array}{c}\text { Metodologias de } \\
\text { esterilização }\end{array}$ & Alho & Canela & $\begin{array}{c}\text { Cravo- } \\
\text { da-índia }\end{array}$ \\
\hline Testemunha & $0,64 \mathrm{a}$ & $0,55 \mathrm{a}$ & $0,62 \mathrm{a}$ \\
Autoclavagem a $120^{\circ} \mathrm{C}$ & $0,51 \mathrm{~b}$ & $0,38 \mathrm{~b}$ & $0,00 \mathrm{~b}$ \\
Autoclavagem a $100^{\circ} \mathrm{C}$ & $0,50 \mathrm{~b}$ & $0,35 \mathrm{c}$ & $0,00 \mathrm{~b}$ \\
Banho maria & $0,16 \mathrm{c}$ & $0,35 \mathrm{c}$ & $0,00 \mathrm{~b}$ \\
Filtragem & $0,09 \mathrm{~d}$ & $0,34 \mathrm{c}$ & $0,00 \mathrm{~b}$ \\
\hline CV $(\%)$ & 0,93 & 0,46 & 0,09 \\
\hline
\end{tabular}

Médias seguidas pela mesma letra nas colunas, não diferem entre si pelo teste de Tukey a $5 \%$ de probabilidade.

A maior variação relatada na taxa de crescimento micelial em função das metodologias de esterilização e/ou desinfestação foi observada com o uso do extrato aquoso de alho, onde o fungo de 0,64 $\mathrm{cm}$ ao dia, no tratamento controle, passou a apresentar crescimento de apenas $0,09 \mathrm{~cm} \mathrm{dia}^{-1}$ quando o extrato foi filtrado. Vale salientar que a produção de esporos está relacionada, além de condições climáticas ideais, ao tamanho da colônia fúngica, pressupondo que a colônia que apresente menor crescimento micelial, também venha a produzir menor quantidade de fonte de inóculo.

A taxa de crescimento micelial de $F$. solani verificada quando o mesmo foi submetido ao extrato aquoso de canela, independente da metodologia de esterilização adotada, não representou elevada redução em relação ao tratamento controle. Este comportamento pode estar relacionado ao local ou mesmo à época do ano em que a planta foi coletada, pois de acordo com Ming (1994) a utilização de planta medicinal é tão complexa quanto à própria composição, sendo que, do cultivo à comercialização, alterações consideráveis podem ocorrer, comprometendo a qualidade e a quantidade dos princípios ativos. Di Stasi (1996) afirma ainda que a concentração de princípios ativos não se apresenta uniforme no decorrer do ciclo da planta, podendo apresentar variações conforme as condições de cultivo, a colheita e o processamento do material vegetal.

Nas condições em que os ensaios experimentais foram conduzidos pode-se concluir que independente da metodologia de esterilização e/ou desinfestação utilizada o extrato aquoso de cravoda-índia suprime completamente o desenvolvimento de Fusarium solani. A atividade antifúngica do extrato aquoso de alho é influenciada negativamente pelo 
aumento da temperatura das metodologias de esterilização e/ou desinfestação, evidenciando que o princípio ativo desta planta apresenta termosensibilidade, enquanto as propriedades antifúngicas do extrato aquoso de canela são comprometidas apenas quando esterilizado por autoclavagem a $120^{\circ} \mathrm{C}$.

\section{AGRADECIMENTO}

A CAPES pela concessão da bolsa e a Embrapa Soja pelo fornecimento do isolado fúngico.

\section{REFERÊNCIA}

BALARDIN, C.R. et al. Possibilidade de transmissão de Fusarium solani f.sp. glycines, agente causal da podridão vermelha da raiz da soja, através da semente. Fitopatologia Brasileira, v.30, n.6, p.574-81, 2005.

$\mathrm{BENICIO}$, V. et al. Identificação e características culturais de espécies do gênero Aspergillus isoladas de sementes de feijão no Estado da Paraíba. Fitopatologia Brasileira, v.28, n.2, p.180-3, 2003.

BIANCHINI, A.; MARINGONI, A.C.; CARNEIRO, S.M.T.P.G. Doenças do Feijoeiro. In: KIMATI, H. et al. (Eds.). Manual de Fitopatologia: doenças de plantas cultivadas. 4.ed. São Paulo: Agronômica Ceres, 2005, p.333-49.

BONALDO, S.M. et al. Fungitoxicidade, atividade elicitora de fitoalexinas e proteção de pepino contra Colletotrichum lagenarium pelo extrato aquoso de Eucalyptus citriodora. Fitopatologia Brasileira, v.29, n.2, p.128-34, 2004.

CARNEIRO, S.M.T.P.G. Efeito de extratos de folhas e do óleo de nim sobre o oídio do tomateiro. Summa Phytopathologica, v.29, n.3, p.262-5, 2003.

CARNEIRO, S.M.T.P.G.; PIGNONI, E.; GOMES, J.C. Efeito do nim (Azadirachta indica A. Juss.) no controle da mancha angular do feijoeiro. Revista Brasileira de Plantas Medicinais, v.10, n.3, p.6-10, 2008.

CELOTO, M.I.B. et al. Atividade antifúngica de extratos de plantas a Colletotrichum gloeosporioides. Acta Scientiarum, v.30, n.1, p.1-5, 2008.

DI STASI, L.C. (Ed.). Plantas medicinais: arte e ciência. Um guia de estudos multidisciplinar. São Paulo: Ed. Universidade Paulista, 1996. 215p.
FRANZENER, G. et al. Atividade antifúngica e indução de resistência em trigo a Bipolaris sorokiniana por Artemisia camphorata. Acta Scientiarum, v.25, n.2, p.503-7, 2003.

GHINI, R.; KIMATI, H. Resistência de fungos a fungicidas. Jaguariúna: Embrapa Meio Ambiente, 2000. 78p.

GHINI, R.; NAKAMURA, D. Seleção de antagonistas e nutrientes que induzem supressividade de solos a Fusarium oxysporum f. sp. phaseoli em microcosmos e in vivo. Summa Phytopathologica, v.27, n.3, p.318-22, 2001. KE-QIANG, C.; VAN BRUGGEN, A.H.C. Inhibitory efficacy of several plant extracts and plant products on Phytophthora infestans. Journal of Agricultural University of Hebei, v.24, p.108-16, 2001.

LEMOS, T.L.G. et al. Antimicrobial activity of essential oils of brazilian plants. Phytotherapy Research, v.4, n.2, p.82-4, 1990.

MING, L.C. Estudo e pesquisa de plantas medicinais na agronomia. Horticultura Brasileira, v.12, n.1, p.2-9, 1994. RIBEIRO, L.F.; BEDENDO, I.P. Efeito inibitório de extratos vegetais sobre Colletotrichum gloesporioides - Agente causal da podridão de frutos de mamoeiro. Scientia Agrícola, v.56, n.4, p.1267-71, 1999.

RODRIGUES, E.A. et al. Potencial da planta medicinal Ocimum gratissimum no controle de Bipolaris sorokiniana em sementes de trigo. Acta Scientiarum, v.28, n.2, p.213-20, 2006.

ROZWALKA, L.C. et al. Extratos, decoctos e óleos essenciais de plantas medicinais e aromáticas na inibição de Glomerella cingulata e Colletotrichum gloeosporioides de frutos de goiaba. Ciência Rural, v.38, n.2, p.301-7, 2008.

SCHWAN-ESTRADA, K.R.F.; STANGARLIN, J.R.; CRUZ, M.E.S. Uso de extratos vegetais no controle de fungos fitopatogênicos. Revista Floresta, v.30, p.129-37, 2000. SOUZA, A.E.F.; ARAÚJO, E.; NASCIMENTO, L.C. Atividade antifúngica de extratos de alho e capim-santo sobre 0 desenvolvimento de Fusarium proliferatum isolado de grãos de milho. Fitopatologia Brasileira, v.32, n.6, p.46571, 2007.

STANGARLIN, J.R. et al. Plantas medicinais e controle alternativo de fitopatógenos. Biotecnologia Ciência \& Desenvolvimento, n.11, p.16-21, 1999.

TEIXEIRA, $\mathrm{H}$. et al. Efeito de diferentes fontes de luz no crescimento e esporulação in vitro de fungos fitopatogênicos. Ciência e Agrotecnologia, v.25, n.6, p.1314-20, 2001. 